\title{
Dina Salústio e a violência de gênero na literatura cabo-verdiana
}

\author{
Geni Mendes de Brito ${ }^{1}$ \\ Tânia Maria de Araújo Lima²
}

Com o desenvolvimento do pensamento feminista a partir de 1960, a mulher passou a ser objeto de estudo em diversas áreas do conhecimento, na tessitura da literatura, da sociologia, do estudo literário, da filosofia, da antropologia, bem como da psicanálise. De lá para cá, houve um grande avanço nos estudos que abordam o papel da mulher nos variados contextos em que ela está inserida.

As mulheres engendraram uma subcultura dentro dos limites da sociedade regulada pela ideologia patriarcal, assim como o fizeram os grupos minoritários: negros, índios, homossexuais, transexuais, etc. (SHOWALTER, 1985 apud Zolin, 2009). Sob essas condições, as mulheres escritoras construíram uma tradição literária que vem se destacando desde "Maio de 68" aos dias atuais. A literatura escrita por mulheres vem buscando insistentemente a própria identidade feminina, que, por muitos séculos, ficou escondida e foi massacrada pelo patriarcado ao longo da história da humanidade mundo afora.

Este texto busca compreender a subjetividade da mulher cabo-verdiana em situação de violência de gênero a partir de uma reflexão antropológica e literária. $\mathrm{O}$ conceito de gênero é bastante discutido entre intelectuais de diversas camadas sociais, diferentes manifestações religiosas e culturais. Para Saffioti (2004), o termo gênero pode englobar tanto relações não hierarquizadas como relações em que ocorra a dominação-exploração de um sexo sobre o outro. E dentro da categoria gênero, podem-se localizar as relações homem-homem e mulher-mulher, entretanto, é mais comum o uso do termo para designar relações entre os sexos opostos. Scott (1995, p. 86) analisa o gênero como uma "referência com base na qual se decodificam o sentido e a complexidade das relações sociais.” A autora fala das relações

1 Doutoranda no Programa de Pós-Graduação em Estudos da Linguagem da Universidade Federal do Rio Grande do Norte (Ufre), Natal, Rn, Brasil. E-mail: geni-mendes@hotmail.com

2 Doutora em Letras e professora do Programa em Pós-Graduação em Estudos da Linguagem da Universidade Federal do Rio Grande do Norte (UfRN), Natal, RN, Brasil. E-mail: tanialimapoesia@yahoo.com 
de poder e das desigualdades sociais entre os sexos, em que na maioria dos casos, o sexo feminino está em desvantagem.

Para essa reflexão, apresentamos o conto "Foram as dores que o mataram" presente no volume Mornas eram as noites (1994), da escritora Dina Salústio. ${ }^{3}$

Mornas eram as noites é um livro de contos com 35 narrativas curtas em que é apresentado, em um contexto multifacetado, um arsenal de temas híbridos e associados a situações vividas por mulheres cabo-verdianas. Dina Salústio afirma que é "uma mulher que escreve umas coisas" (Gomes, 2008, p. 218), que "conta estórias de mulheres" em um universo identitário regido pelo signo da alteridade. Porta-retrato das minorias silenciadas, na percepção de Salústio, estas mulheres sem nome, sem rosto, sem voz, trazem ao palco os problemas que tocam as mulheres em diferentes contextos sociais e culturais do mundo ao redor. Mornas eram as noites não passa despercebido aos olhos do leitor atencioso. O conceito de morna está associado a diferentes significados. Morna é modalidade musical típica de Cabo Verde, mas é também uma modalidade poética em que os povos insulares expressam a alegria, a dor, a nostalgia, o amor. Morna traduz todo o sentimento nacionalista que identifica o cabo-verdiano. A pesquisadora Simone Caputo Gomes explica que "Morna" define as crônicas da vida cantadas por mulheres, e, nessas crônicas, estão presentes o ambiente doméstico e todos os sentimentos existenciais do cotidiano feminino (Gomes, 200o, p. 115).

$\mathrm{Na}$ arte de contar as mornas, Dina Salústio reinventa o cotidiano de mulheres que estão inseridas no mundo doméstico feminino. Percebe-se na prosa salustiana as pegadas dos avanços à emancipação das mulheres, as violências sociais, as discriminações sofridas, a iniciação sexual, assim como a gravidez precoce, a falta de planejamento familiar, a prostituição, os emblemas sociais ainda visíveis no quadro de exclusão das mulheres cabo-verdianas. As figuras femininas expostas na escrita de Salústio são diferenciadas e representam um amplo apanhado de todas as classes sociais e de diferentes idades.

Diante da variedade de produções femininas pelo mundo, a produção literária em Cabo Verde traz à tona textos cujos temas revelam as experiências sociais das mulheres cabo-verdianas, que, em situações insalubres, são tomadas como representantes de inúmeras realidades com dilemas de violência. Atualmente, Dina Salústio é uma das ficcionistas mais conhecidas da literatura

3 Bernadina Oliveira Salústio - conhecida como Dina Salústio. Natural da Ilha de Santo Antão (1941), Cabo Verde. 
cabo-verdiana, que, através da poesia e do ensaio, vem despertando no leitor o interesse de conhecer melhor a jovem literatura cabo-verdiana. A produção literária do arquipélago é hoje bem vista pela crítica, "inaugura uma nova maneira de dizer o mundo a partir de Cabo Verde" (Gomes, 20oo, p. 115).

Com o objetivo de ilustrar essa situação, far-se-á uma abordagem crítica, sob a ótica de alguns teóricos dos estudos literários e antropológicos. No conto "Foram as dores que o mataram", observa-se fragmentos de uma violência que se institui no corpo do imaginário fêmeo:

Não importa o dia. Nem importa mesmo o ano em que se conheceram. Aconteceu. E houve um momento em que se amaram. Talvez tenha havido muitos momentos em que se amaram.

Depois, a rotina de vidas que se afastaram, e, incompreensivelmente, continuam juntas. E, dramaticamente caminham juntas, num desafio permanente à vida, ao direito de viver.

Não matei o meu marido. Eu o amava. Por que matá-lo?

Foram as dores do meu corpo que o condenaram. Foi o sangue pisado, o ventre moído, as feridas em pus.

Foram as pancadas de ontem, as de hoje e, sobretudo, as pancadas de amanhã que o mataram.

Eu amava-o. Por que matá-lo?

Foi o meu corpo recusado e dorido após o uso e os abusos. Foram a tristeza, o desespero e a dor do amor que não tinha troco.

Eu amava-o. Por que matá-lo?

Às vezes ficava à janela, meio escondida, vendo-o partir para o trabalho com a roupa que eu lavara e engomara.

Gostava do seu modo de andar, do jeito como inclinava a cabeça. Via-o partir e ali ficava horas à espera que voltasse e me trouxesse um riso e a esperança de que as coisas iriam mudar. Nesse dia não lembraria mais os tempos duros, os paus de pedra que me roíam e me desgastavam as entranhas. Mas para mim, não voltava nunca. Apenas para pedaços de meu corpo que esquecia logo. Eu amava-o. Por que matá-lo?

Ele matou-se. Criou um espaço onde coabitavam a violência, a destruição, a miséria, o animalesco. E nós.

Deu-me armas e fez-me assassina. ... Depois ficou tudo escuro. E o corpo a doer, a doer, a doer, a...

Um soluço frágil absorve a última palavra (SALÚstio, 1994, p. 21-22).

A temática do conto mostra a "conjugal-idade" entre um homem e uma mulher e a violência baseada no gênero, discutida e questionada do ponto de vista feminino. O conto está dividido em quatro partes: na primeira parte 
percebe-se a voz do narrador fazendo uma espécie de apresentação do conto. O discurso é de um tempo sem data, pois não apresenta uma temporalidade bem definida, documenta um fato que se estende na sociedade de Cabo Verde. O conto se inicia sem localização no tempo, indicando que a situação vivida pelo casal é secular: "Não importa o dia. Nem importa mesmo o ano em que se conheceram. Aconteceu. E houve um momento em que se amaram. Talvez tenha havido muitos momentos em que se amaram" (SALÚstio, 1994, p. 21).

A violência baseada em gênero ocorre principalmente no interior da família, inclusive entre pessoas que se amaram, como ressalta a contadora, porém há ausência de igualdade na relação. Com o passar do tempo, o recrudescimento dos conflitos concorre para que uma das partes, quase sempre a mulher, acabe sendo oprimida e até mesmo vítima de violência: "Depois, a rotina de vidas que se afastaram, e, incompreensivelmente, continuam juntas. E, dramaticamente caminham juntas, num desafio permanente à vida, ao direito de viver" (SALÚstio, 1994, p. 21).

Percebemos no texto que a violência doméstica é produto de um padrão de relações assimétricas entre homem e mulher, legitimado pela ideologia patriarcal dominante e favorecido pela forma como a mulher se encontra sujeita aos desígnios socioeconômicos e culturais prevalecentes.

Os estudos sobre violência de gênero e a discussão sobre o patriarcado derivaram de pesquisas sobre a mulher e sobre a contribuição do movimento feminista. A violência contra a mulher é uma ação ou conduta baseada no gênero, que causa morte, dano ou sofrimento físico, sexual ou psicológico, tanto no âmbito público quanto privado. As violências baseadas em gênero são agudizadas pelas desigualdades sociais, ou seja, há uma sobreposição entre os sistemas de dominação, exploração de classe, gênero e etnia. (RAMÃo; Meneghel; Oliveira, 2005, p. 80).

Contribuindo com essa afirmação, Miriam Pillar Grossi (2004) aponta que a dominação masculina é uma das questões teóricas que fica no epicentro das reflexões sobre gênero. Desde o final de 1970, a opinião geral era que a dominação masculina seria universal, presente em todas as culturas; simbolicamente, politicamente e economicamente, os homens dominavam as mulheres. Hoje, grande parte dos autores concorda que essa dominação ainda existe na maior parte das diferentes culturas do planeta. 
Para entendermos a razão da desigualdade entre os gêneros, é importante conhecermos como se deu a construção social da dominação masculina. Anette Goldeberg (1989) afirma que as origens das desigualdades sexuais e de opressão feminina se encontram no "patriarcado", tipo de supremacia e dominação masculina presente em todas as sociedades históricas e em todas as relações sociais, responsável pela exclusão sistemática das mulheres em todas as instâncias de poder, mas também pela permanente desvalorização dos papéis e tarefas a elas atribuídas (GOLDEBERG, 1989, p. 8).

Ainda segundo Grossi (2004), a fim de manter a hegemonia masculina, o sistema patriarcal criou estratégias para tornar a mulher um objeto simbólico. Estabeleceu a divisão social do trabalho com base no sexo, construindo assim a dicotomia da inferioridade feminina e superioridade masculina - reservou ao homem o espaço público, de melhor prestígio e melhor remunerado, enquanto à mulher foi dedicado o espaço privado, com baixa remuneração. Com o discurso da diferença biológica, os papéis sociais foram reforçados, atribuindo às mulheres características tidas como naturais, como cuidar dos filhos e da casa. A família, a Igreja e a mídia contribuíram diretamente no processo que levou à desigualdade entre os gêneros (Grossi, 2004, p. 15-16). Porém, essa relação de desigualdades entre o masculino e o feminino passou a ser questionada por importantes movimentos sociais capazes de abalar a estrutura do sistema patriarcal. Tanto o movimento feminista como os movimentos gays e juvenis deram grande contribuição a partir dos questionamentos da desigualdade baseada no gênero.

Na segunda parte do conto, percebe-se que a vítima atribui à agressão: "as dores do corpo", "o sangue pisado", "o ventre moído", “as feridas em pus", "o medo", "as pancadas de ontem, as de hoje e, sobretudo, as pancadas de amanhã", "as dores da alma", "a tristeza, o desespero e a dor do amor que não tinha troco". Dina Salústio constrói uma situação em que a mulher é vitima da violência psicológica e física no seio familiar e, por ser vítima, a narradora redime-a da culpa de ter matado o marido, transferindo-a para as torturas e pancadas infringidas por ele. Em discurso direto, a personagem feminina aparece para se defender contra a acusação de assassinato do marido. O leitor é o tempo todo informado da violência praticada pelo marido: "Não matei o meu marido. Eu o amava. Por que matá-lo?” (SAlústio, 1994, p. 21). 
A personagem feminina tinha consciência de que sofreria violência doméstica enquanto houvesse relacionamento conjugal, pois o companheiro não mudava a forma de lidar com os afetos. Ao redor do mundo, enquanto o homem utiliza-se da violência de forma constante para impor sua vontade e afirmar-se, a mulher usa a violência como meio de livrar-se da situação a que está submetida. O momento do conflito se apresenta anterior à morte do marido e ilustra muito bem a situação do "patriarcado" que, segundo Heleieth Saffioti (1976/2004), é o sistema masculino de opressão das mulheres. Por baixo dos travesseiros da história, ainda segundo a autora, o conceito foi redefinido como um conjunto de relações sociais que tem uma base material e no qual há relações hierárquicas entre homens e o pacto de solidariedade que existe fortemente entre eles é o que os habilita a controlar as mulheres.

A ideologia patriarcal, aliada à opressão imposta pelo colonialismo, valeu-se de estratégias autoritárias para excluir as mulheres das escalas e atividades de prestígio na sociedade, inclusive no tocante à autoria literária. No bojo desse processo, a ordem androcêntrica perpetrou também outra forma de violência, que reduzia a mulher ao espaço restrito do claustro privado do cotidiano, subjugando-a perante os domínios masculinos oriundos do espaço público.

Constata-se que os primeiros estudos sobre a violência contra a mulher postularam que a violência acontecia em todas as classes sociais, porém existe o consenso de que há um agravamento quando a discriminação de gênero soma-se à racial. Por exemplo, quando mulheres negras tentam prestar queixa policial, enfrentam dificuldades, em virtude do racismo dos policiais para com o povo negro. Além das dificuldades econômicas, outras situações como o desemprego, a pobreza, a falta de qualificação profissional, as relações conjugais problemáticas e a responsabilidade com os filhos fazem com que essas mulheres sintam-se deprimidas, desmotivadas, doentes, o que gera uma situação conflitiva e constrangedora no seu cotidiano, por serem mulheres, pobres e negras (RAmão; MEneghel; Oliveira, 2005, p. 82).

De acordo com as autoras do artigo "Nos caminhos de Iansã: cartografando a subjetividade de mulheres em situação de violência de gênero" (2005), para a maioria dessas mulheres, o lar já não representa um espaço de proteção. Até pouco tempo, a violência intrafamiliar era tratada como um assunto de caráter privado. A dicotomia entre espaço público e espaço privado (com conotação 
hierárquica designada a cada sexo) surge como marco de análise a fim de explicar a subordinação da mulher dentro do lar. De acordo com esse enfoque, a autoridade do homem estende-se a todos os níveis da vida social, pública e privada, justificando-se pela sua inserção no trabalho produtivo. Por outro lado, à mulher, destina-se o espaço doméstico restrito e controlado, sendo esta colocada em posição de inferioridade no conjunto das relações sociais. Em virtude disso, muitas vezes, a mulher assumiria comportamentos dependentes.

$\mathrm{Na}$ terceira parte do conto, a vítima recorda um tempo já distante, em que as formas verbais "ficava", "gostava", "via”, transportam-na para um tempo regido por admiração e felicidade. O texto é fragmentado pelas lembranças e, de forma ligeiramente poética, mostra sentimentos nostálgicos de um passado que não pode mais ser revivido.

Às vezes ficava à janela, meio escondida, vendo-o partir para o trabalho com a roupa que eu lavara e engomara. Gostava do seu modo de andar, do jeito como inclinava a cabeça. Via-o partir e ali ficava horas à espera que voltasse e me trouxesse um riso e a esperança de que as coisas iriam mudar. Nesse dia não lembraria mais os tempos duros, os paus de pedra que me roíam e me desgastavam as entranhas. Mas para mim, não voltava nunca, apenas para os pedaços de meu corpo que esquecia logo (SALÚstio, 1994, p. 21-22).

No ensaio intitulado "Cenas e queixas: mulheres e relações violentas", Maria Filomena Gregori (1992, p. 164) salienta que ser vítima significa aderir a uma imagem de mulher que está na posição de vítima ao pedir um auxílio, é se colocar na posição de alguém que busca amparo.

$\mathrm{Na}$ quarta parte do conto, o papel de vítima é assumido pela mulher, assim como dois outros: o papel de agressora e o de acusadora. Aos poucos, a autodefesa adquire a forma de uma acusação. Ela cria também um espaço em que predomina a violência e a morte. $\mathrm{Na}$ ótica da esposa violentada, o responsável pela própria morte é o marido, por criar e fomentar um ambiente de violência em sua própria casa. Ela expõe as condições que a levaram ao ato e, através de fatos descritos, quer mostrar que é isenta de culpa. "A personagem feminina de Dina Salústio não aceita passivamente essa realidade de agressões: ela rebela-se, revolta-se, queixase, sente ódio, grita e mata” (QueIROZ, 2010, p. 130).

Ele matou-se. Criou um espaço onde coabitavam a violência, a destruição, a miséria, o animalesco. E nós. Deu-me armas e fez-me assassina. ... Depois ficou tudo escuro. E o corpo a doer, a doer, a doer, a... (SALústio, 1994, p. 22). 
O conto termina com a volta do narrador participando de forma solidária no fechamento do cenário. É como se o palco da vida se fechasse para uma nova cena. Um soluço frágil corta o relato da mulher, deixando em aberto ao leitor uma gama de sentimentos conflitantes que abrangem dor, coragem, privação dos sentidos, amor, e quem sabe, arrependimento por rebater violência com violência: "Um, soluço frágil absorve a última palavra" (SALÚstio, 1994, p. 22).

A mulher representada no conto de Dina Salústio não tem nome, é anônima, pois assim simboliza muitas outras mulheres tanto em Cabo Verde como no resto do mundo, que são abusadas, violentadas e reprimidas. A personagem radicaliza um tipo de revolta, pelas dores sofridas, pela vida roubada em diferentes aspectos e, principalmente, pela falta de esperança. Matar o marido aqui significa um ato de desespero, de grito ocasionado pela violência e pelo desamor sofrido. Embora o quadro social e legal tenha mudado, a violência de gênero continua a fazer parte do cotidiano de muitas mulheres, articulando outras vulnerabilidades sociais e econômicas e alicerçando-se nas desigualdades das relações de gênero. São essas relações que encerram a mulher numa malha de dependências que marca o seu processo de vítima e que condiciona a sua forma de olhar a violência.

O Artigo $1^{\circ}$ da Convenção para Eliminação de Todas as Formas de Discriminação Contra a Mulher (DELGADo, 2007, p. 22) aponta que as causas mais prováveis da violência doméstica em Cabo Verde são: a condição socioeconômica; o machismo, ou sentimento de superioridade do homem sobre a mulher, especialmente nas classes menos favorecidas economicamente; o desemprego; o alcoolismo e o consumo de drogas. A violência sexual, física e psicológica também é uma realidade presente no cotidiano da mulher cabo-verdiana.

García-Moreno (2002, p. 92) apresenta o conceito de violência contra a mulher em diferentes aspectos: violência doméstica, violência de gênero e violência contra mulheres são termos utilizados para denominar esse grave problema que degrada a integridade da mulher. A violência de gênero pode manifestar-se através de violência física, violência psicológica, violência sexual, violência econômica e violência no trabalho.

A filósofa e feminista Marilena Chauí (Chauí, 1985 apud Santos; Izumino, 2005, p. 3), afirma que "a violência contra as mulheres é o resultado de uma 
ideologia de dominação masculina que é produzida e reproduzida tanto por homens como por mulheres". Acrescentando que essa violência contra a mulher é tão somente uma "flagrante manifestação de poder" (ARENDT, 1994, p. 32), Hannah Arendt reforça a questão da dominação, quando explica:

Ao que parece, a resposta dependerá do que compreendemos como poder. E o poder, ao que tudo indica, é um instrumento de dominação, enquanto a dominação, assim nos é dito, deve a existência a um "instinto de dominação". Lembramo-nos imediatamente do que Sartre disse a respeito da violência quando em Jouvenel que um homem sente-se mais homem quando se impõe e faz dos outros um instrumento de sua vontade, o que lhe dá um "prazer incomparável" (ARENDT, 1994, p. 33).

Nas sociedades atuais, convivemos com várias formas de violência. A violência que é decorrente dos altos índices de desigualdade social e da pobreza generalizada provoca outras violências, como aquelas que são praticadas pela discriminação contra as minorias, tais como negros, índios, mulheres, crianças e idosos. Essa violência, ainda segundo Chauí, "é uma ação que transforma diferenças em desigualdades hierárquicas com o fim de dominar, explorar e oprimir", tratando o ser dominado como "objeto" e não como "sujeito", silenciando-o e tornando-o dependente e passivo (CHAUÍ, 1985, p. 36). Já para Saffioti, (2004), a mulher não é assim tão passiva e dependente, pois com sua pequena parcela de poder, dentro de uma relação de subordinação, ela questiona essa supremacia masculina e encontra meios de resistência. A autora defende que, dentro do binômio dominação-exploração da mulher, os dois polos da relação possuem poder, mas de maneira desigual. É o que Saffioti denomina de micropoderes quando afirma:

Existem, todavia, micro-poderes, ou seja, segmentos populacionais dotados da capacidade de deles fazer uso. Se não conseguem revolucionar o mundo de forma acelerada, fazem-no em espaços capazes não só de colaborar para a transformação da sociedade, como também de tecer uma malha social de sustentação das conquistas realizadas nos processos macro (SAFFIOTI, 2004, p. 30 ).

Ao tomar a responsabilidade pela educação dos filhos e pelos cuidados domésticos, a mulher desenvolve estratégias de reação e resistência à dominação masculina, ao mesmo tempo em que pode desenvolver mecanismos de negação dos papéis sociais impostos ao sexo feminino. Ainda que limitada, a mulher detém uma parcela significativa de poder sociocultural, que a torna 
capaz de interferir na construção da subjetividade e da condição masculina, negando assim, sua total condição de passiva e dependente (BorIs, 2004).

A violência faz com que a vítima perca sua autonomia, sua autodeterminação para pensar e agir como queira. A violência contra a mulher está ligada diretamente ao preconceito e ao abuso de poder cometido pelo homem, diante da vulnerabilidade feminina.

Reforçando a questão sobre a violência contra as mulheres, em seu livro intitulado A dominação masculina, Pierre Bourdieu (2002, p. 49-50) aponta que a dominação do homem sobre a mulher é exercida por meio de uma violência simbólica, compartilhada inconscientemente entre dominador e dominado e determinada pelos esquemas práticos do habitus. Pierre Bourdieu descreve a violência simbólica como um ato sutil que oculta relações de poder que alcançam não apenas as relações entre os gêneros, mas toda a estrutura social. Não é à toa que o sociólogo afirma que uma relação desigual de poder comporta uma aceitação dos grupos dominados, não sendo necessariamente uma aceitação consciente e deliberada, mas principalmente de submissão préreflexiva.

Como em toda dominação, os esquemas de pensamento dominantes influenciam também os dominados, que acabam por legitimar ainda mais a dominação. Nessa lógica, as próprias mulheres acabariam, segundo Bourdieu, por reproduzir as representações que as depreciam na ordem social. E essa reprodução sobre a mulher surge desde a Idade Média, quando Graciano afirma em seu discurso dominical: "A mulher não tem poder, mas em tudo ela está sujeita ao controle do seu marido". Com essa afirmação, esse monge italiano que viveu no século XI estava expressando uma das crenças universalmente aceitas: a inferioridade inerente e insuportável das mulheres (RICHARDS, 1993, p. 35). Em Sexo, desvio e danação, Jeffrey Richards afirma que "as teorias sobre o papel da mulher haviam sido desenvolvidas pelos padres da Igreja. Esta visão da inferioridade da mulher era uniformemente divulgada nos tratados teológicos, médicos e científicos, e ninguém a questionava” (Richards, 1993, p. 36). A lei canônica permitia especificamente o espancamento da esposa, e isso acontecia em todos os níveis da sociedade.

A respeito da sociedade moderna, Marilena Chauí afirma, ainda, que "as mulheres são cúmplices da violência e contribuem para a reprodução de sua dependência porque são instrumentos da dominação masculina" 
(Chauí, 1985 apud Santos; Izumino, 2005, p. 4). Contrária a essa afirmação de Chauí, Saffioti (2004) defende que a violência contra as mulheres é resultado de uma sociedade com valores patriarcais que estabelece uma espécie de cumplicidade entre homens. Nesse contexto, as mulheres são controladas e submetidas à dominação masculina.

Se, na famosa frase de O segundo sexo (1970), a escritora francesa Simone de Beauvoir afirma que "ninguém nasce mulher, torna-se mulher", a escritora Dina Salústio, em entrevista concedida a Simone Caputo Gomes, afirma que "em Cabo Verde, quando nasce uma menina, ela já é uma mulher" (Gomes, 200o, p. 114). Enquanto a frase de Beauvoir inspirou muitas gerações de mulheres a mergulhar no verdadeiro significado da condição feminina no passado e no presente, Dina Salústio "propõe uma espécie de estigma que marca as meninas cabo-verdianas desde o nascimento, em que estas carregarão o peso da discriminação social, da pobreza, da violência que sofrerão na carne por ser mulher" (QUEIROZ, 2010, p. 106).

Em Cabo Verde, após a independência em 1975, muitas foram as conquistas sociais para as mulheres, inclusive no campo literário. Atualmente, a autoria feminina procura, sobretudo, dar visibilidade e voz à historicidade das mulheres (Gomes, 2008, p. 277). Além de Dina Salústio, escritoras como Orlanda Amarilis, Ivone Aída, Fátima Bettencourt, Vera Duarte, entre outras, utilizamse da poesia como canal de divulgação e luta contra a opressão masculina, por meio do qual essas autoras procuram conscientizar e elevar a autoestima das mulheres do arquipélago.

Ao escrever o conto "Foram as dores que o mataram", Dina Salústio faz uma denúncia da violência contra a mulher como violência velada. Palavras bonitas, como "passividade", "dedicação", "sinceridade", "fidelidade" escondem sentimentos de dor e abandono, de tristeza e solidão, de vida e violências que se fazem presentes em diferentes contextos nos quais vive a mulher.

Conforme Maria Teresa Salgado, todas as histórias de Mornas eram as noites tratam de temas amplamente abordados na literatura: a solidão, o medo, a violência social, a miséria, a frustração dos desejos e expectativas.

No entanto, por mais dolorosas que sejam as cenas aí retratadas, o saldo final é o do mergulho do narrador no texto, nutrindo-o a partir de suas experiências pessoais, não como alguém mais sábio, mas como alguém capaz de captar 
Geni Mendes de Brito

TÂNIA MARIA DE ARAújo LiMA

admiravelmente experiências e emoções, compartilhando-as com o leitor (SAlgado, 2008, p. 39).

Essa compreensão encontra amparo no pensamento de Walter Benjamin. O crítico literário e filósofo alemão aborda a figura do narrador, não mais como um sábio, mas como aquele que é capaz de dar um conselho e cuja tarefa é "trabalhar a matéria-prima da experiência - a sua e a dos outros transformando-a num produto sólido, útil e único” (BENJAMIN, 1987, p. 221 apud SAlgado, 2008, p. 36), como o faz Dina Salústio em cenas curtas, porém contundentes. A escritora constrói suas histórias a partir das experiências vividas no seu contexto, por vezes angustiantes, tristes, bem-humoradas, por vezes cheias de sonhos e esperanças. A autora toma posições frente às situações apresentadas na narrativa, coloca-se no lugar das companheiras de luta e toma para si a responsabilidade de compreendê-las. Numa luta engajada com a questão de gênero, revela a subjetividade feminina e as aprendizagens possíveis a partir de circunstâncias que envolvem as experiências das mulheres.

Ao ler os contos de Dina Salústio, o leitor é esclarecido sobre a situação das mulheres em Cabo Verde, visto que eles expõem a subjetividade das mulheres, sejam personagens ou narradoras, revelando, por suas próprias vozes e pelo seu íntimo, o universo feminino. O conto "Foram as dores que o mataram", acima apresentado, atesta a violência a que muitas mulheres são submetidas. São mulheres sem voz e sem rosto, são as anônimas, as passantes, trazidas ao palco pela escrita de Dina Salústio que, ao promoverem uma releitura da história literária e cultural de Cabo Verde, falam, escrevem e gritam.

\section{Referências}

Arendt, Hannah. Sobre a violência. Rio de Janeiro: Relume Dumará, 1994.

BeAuvorr, Simone. O segundo sexo. São Paulo: Difusão Europeia do Livro, 1970.

Benjamin, Walter. O narrador. In: Benjamin, Walter. Obras escolhidas: magia e técnica, arte e política. 2. ed. São Paulo: Brasiliense, 1986, v. 1.

Boris, Georges Daniel Janja Bloc. Falas masculinas ou ser homem em Fortaleza: múltiplos recortes da construção da subjetividade masculina na contemporaneidade. In: AmARAL, Célia Chaves Gurgel et al. Teoria e práxis dos enfoques de gênero. Salvador: Redor, 2004.

Bourdieu, Pierre. A dominação masculina. Tradução de Maria Helena Kühner. Rio de Janeiro: Bertrand Brasil, 2002.

Chauí, Marilena. Participando do debate sobre mulher e violência. In: Franchetto, Bruna; Cavalcanti, Maria Laura; Heilborn, Maria Luiza (Orgs.). Perspectivas antropológicas da mulher. São Paulo: Jorge Zahar, 1985, v. 4. 
Delgado, Liriam Tiujo (Org.). Cabo Verde e a CEDAw. Relatório à Convenção sobre a Eliminação de Todas as Formas de Discriminação contra as Mulheres e Documentos Conexos. Praia: ICIEG, 2007.

GARCíA-Moreno, Claudia. Violência perpetrada por parceiros íntimos. In: WHO - WORLD HEALTH ORGANIZATION. World report on violence and health. Genebra: OMS, 2002, p. 91-121.

Goldeberg, Anette. Tudo começou antes de 1975: ideias inspiradas pelo estudo da gestação de um feminismo "bom para o Brasil”. In: NEMGE - NÚCLEO DE ESTUDOS DA MULHER E RELAÇÕES SOCIAIS DE GÊNERo. Relações de sexo x relações de gênero. São Paulo: NEMGE, 1989, p. 1-45.

Gomes, Simone Caputo. Cabo Verde: literatura em chão de cultura. São Paulo: Ateliê, 2008.

Gomes, Simone Caputo. Mulher com paisagem ao fundo. In: Sepúlveda, Maria do Carmo; SAlgado, Maria Teresa (Org.). África e Brasil: letras em laços. São Paulo: Atlântica, 2000.

Gregori, Maria Filomena. Cenas e queixas: mulheres e relações violentas. Rio de janeiro: Paz e Terra, 1992.

Grossi, Miriam Pillar. Masculinidades: uma revisão teórica. Antropologia em Primeira Mão, Florianópolis, n. 1, p. 4-37, 2004.

QueIroz, Sônia Maria Alves. Leitura e representação social das mulheres em Cabo Verde: vencendo barreiras. 2010. Dissertação (Mestrado em Estudos Comparados de Literatura de Língua Portuguesa) - Universidade de São Paulo, São Paulo, 2010.

Ramão, Silvia Regina; Meneghel, Stela Nazareth; Oliveira, Carmen. Nos caminhos de Iansã: cartografando a subjetividade de mulheres em situação de violência de Gênero. Revista Psicologia \& Sociedade, Porto Alegre, v. 17, n. 2, p. 17-28, maio/ago. 2005.

Richards, Jeffrey. Sexo, desvio e danação: as minorias na idade média. Rio de Janeiro: Jorge Zahar, 1993.

Saffioti, Heleieth I. B. Gênero, patriarcado, violência. São Paulo: Fundação Perseu Abramo, 2004.

Salgado, Maria Teresa. Noites nada mornas de Dina Salústio: a oportunidade do diálogo. Abril: Revista do Núcleo de Estudos e Literatura Portuguesa e Africanas da UFF, Niterói, v. 1, n. 1, p. 36-40, ago. 2008.

Salústio, Dina. Mornas eram as noites. Praia: Instituto Cabo-Verdiano do Livro e do Disco, 1994.

SAntos, Cecília MacDowell; Izumino, Wânia. Violência contra as mulheres e violência de gênero: notas sobre estudos feministas no brasil. Estudios Interdisciplinarios de América Latina y El Caribe, Tel Aviv, v. 16, n. 1, p. 147-164, 2005.

Santos, Sonia Maria. A oportunidade do grito em Mornas eram as noites, de Dina Salústio. Dissertação (Mestrado em Letras) - Universidade Federal Fluminense, Niterói, 1997.

Scотт Joan Wallach. Gênero: uma categoria útil de análise histórica. Educação \& Realidade, Porto Alegre, v. 20, n. 2, p. 71-99, jul./dez. 1995.

SouzA, Mailza Rodrigues Toledo de. Quando a literatura reflete a vida: retratos da violência de gênero na literatura cabo-verdiana. In: SEMINÁRIo INTERNACIONAL DE LITERATURA Afrolatina, 1, 2012, Uberlândia. Anais... Uberlândia: Edufu, 2012, p. 415-424.

Zolin, Lúcia Osana. Crítica feminista. In: Bonnici, Thomas; Zolın, Lúcia Osana (Org.). Teoria literária: abordagens históricas e tendências contemporâneas. 3. ed. Maringá: Eduem, 2009. 
Recebido em 2 de março de 2017.

Aprovado em 17 de março de 2017.

\section{Resumo/Abstract/Resumen}

\section{Dina Salústio e a violência de gênero na literatura cabo-verdiana}

Geni Mendes de Brito

Tânia Maria de Araújo Lima

O conto "Foram as dores que o mataram", de Dina Salústio, escritora cabo verdiana, traz à lume uma discussão ímpar sobre a realidade de violência a que muitas mulheres estão subjugadas em algumas ilhas de Cabo Verde, mas também em diferentes rincões do mundo. À luz dos estudos e do conceito da Literatura e da Antropologia sobre esta realidade vivenciada por mulheres sofridas, silenciadas, decorrente do machismo e do patriarcado, este ensaio apresenta uma análise sobre violência de gênero que, através da narrativa contemporânea, anuncia um tipo de realidade que se abisma na lente de contato da inscritura africana. Nessa travessia, a artimanha de contar história vem traduzida pelo legado das culturas dos povos insulares.

Palavras-chave: Dina Salústio, literatura cabo verdiana, violência de gênero.

\section{Dina Salústio and the gender violence in Cape Verdean literature}

Geni Mendes de Brito

Tânia Maria de Araújo Lima

The short story "Foram as dores que o mataram" ("It was the pain that killed him") by Cape Verdean writer Dina Salústio sheds light on an unparalleled discussion about the reality of violence to which many women are subjugated, on some islands of Cape Verde, but also in different parts of the world. Thus, this essay presents an analysis of gender violence, in light of the studies and the concepts in Literature and Anthropology, which address this reality experienced by women who have suffered, and were silenced, and mistreated, due to chauvinism and patriarchy. Through the contemporary narrative, which announces a form of reality that is puzzling in the contact lens of African inscription. At these crossroads, the artifice of storytelling emerges, translated by the legacy of the cultures of the island people.

Keywords: Dina Salústio, cape verdean literature, gender violence.

\section{Dina Salústio y la violencia de género en la literatura caboverdiana}

Geni Mendes de Brito

Tânia Maria de Araújo Lima 
El cuento "Foram as dores que o mataram" ("Fueron los dolores los que lo mataron") escrito por Dina Salústio, escritora caboverdiana, trae a la luz una discusión impar sobre la realidad de violencia de que muchas mujeres son víctimas en algunas islas de Cabo Verde, como también en diferentes rincones del mundo. A la luz de los estudios, y del concepto de la Literatura y la Antropología sobre esta realidad vivida por mujeres sufridas, silenciadas, resultado del machismo y del patriarcado, este ensayo presenta un análisis sobre la violencia de género que, a través de la narrativa contemporánea, anuncia una especie de realidad que se abisma en las lentes de contacto de la escritura africana. En esta travesía, la artimaña de la narración viene traducida por el legado de las culturas de los pueblos insulares.

Palabras clave: Dina Salústio, literatura caboverdiana, violencia de género. 